MATEC Web of Conferences 44, 01070 (2016)

DOI: $10.1051 /$ matecconf $/ 20164401070$

(C) Owned by the authors, published by EDP Sciences, 2016

\title{
The Design and Implementation of Financial System Architecture based on J2EE
}

\author{
Dan Niu, Chun Ming $\mathrm{An}^{\mathrm{a}}$ \\ School of Economic Management, Beihua University, Jilin City, China
}

\begin{abstract}
With the rapid development of information technology and economical globalization, the traditional financial system can no longer adapt the great change in e-ecommerce environment. Then new advanced financial administration is needed. In this paper, the way how to perform and improve the functionality of financial system architecture based on J2EE is going to be the focal points in the realm of financial management.
\end{abstract}

\section{General instruction}

Internet to promote business system digital "Internet enterprises have become a node global J2EE of supply chain, business and system information are run electronically, enterprise system objects and system processes can be digitized, system becomes calculable activity" System computability facilitate system automation, enabling digital system "changes the Internet has brought corporate form" in the Internet, driven by the new enterprise systems began to appear, the ecological environment such as online businesses, Internet businesses, virtual enterprises and other "corporate also changed, namely from the original suppliers, manufacturers, vendors to the customer's level of stringtype mode to J2EE-based non-hierarchical parallel mode "Internet further promote the internationalization of enterprises, while at the macro promote the integration of the global economy, as well as the formation of new economic forms, namely: direct economic, J2EE economy."

Internet business to promote e-commerce, "the Internet is the second PC, occurred in the global IT industry in the field of the second wave, which brought major changes in the IT industry and the global economy and society. Impact on business is the most direct and far-reaching the "no matter how large or small businesses, the Internet is unavoidable, it pushes business to e-commerce. Ecommerce will become one way and the way of life of the Internet age important commercial enterprises.

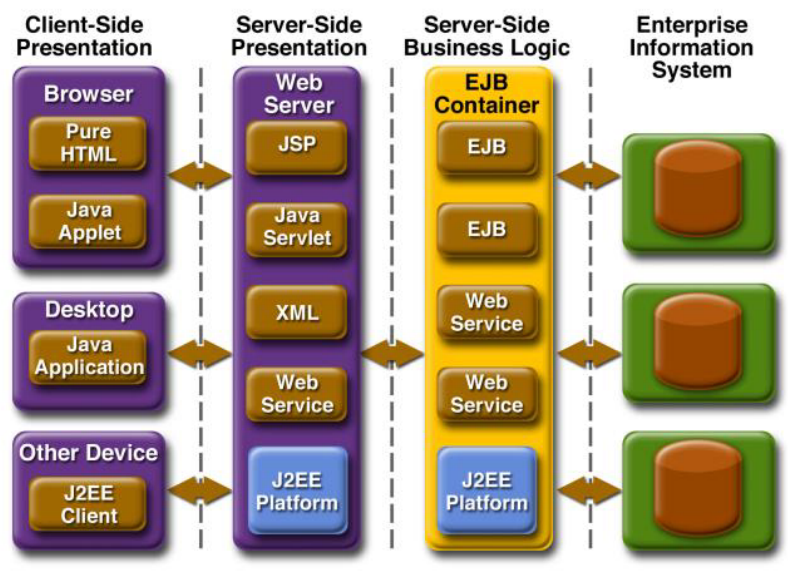

Figure 1. Java 2 Platform, Enterprise Edition (J2EE) Overview

\section{Overview of financial system E- commerce environment}

First, the sale of e-commerce is a way of using advanced IT "transaction parties will own all kinds of input supply and demand of e-commerce J2EE in accordance with the wishes of a certain format, e-commerce J2EE will be based on the user's requirements, and to find relevant information available to the user Choose a variety of trading "Once the user confirms, e-commerce will help complete the signing of the contract, classification, transfer and payment services, such as full payment. This provides a very good way for sellers to sell products at a higher price, the buyer purchases at lower prices for goods and raw materials.

Second, e-commerce is essentially formed a virtual swap market place "it can transcend time and space, in real time to provide users with all kinds of goods and services supply. Development and buyers and sellers, so that buyers and sellers can more easily study the market, more

\footnotetext{
${ }^{\mathrm{a}}$ Corresponding author: chunmingan70@126.com
} 
accurate understanding of the market and grasp the market.

Third, the understanding of e-commerce should be "modern information technology" and "business" two considerations. On the one hand, "electronic commerce" included the concept of "modern information technology" should cover a variety of techniques based on the use of electronic means of communication: the other hand, for the term "commercial" should be interpreted broadly, to include both contract or non-contractual relationship between the various matters of a commercial nature, all caused by "If the" modern information technology "seen as a subset of" business "seen as another subset, the scope of e-commerce should be covered by the two formed by the intersection of subsets, namely under the "ecommerce" title may be widely involved in the Internet, intranet and electronic data interchange for various purposes in the trade.

Fourth, e-commerce is not equal. E-commerce is much more than a real business enterprise foreground electronic, more importantly, the whole operation is a comprehensive information technology system, including the background, including, as well as the optimization and reorganization of business processes of the enterprise as a whole, "that is, to establish a comprehensive enterprise information, based on the implementation of comprehensive control by electronic means of the production, sales, inventory, service and other aspects of human resources is the e-commerce in the true sense.

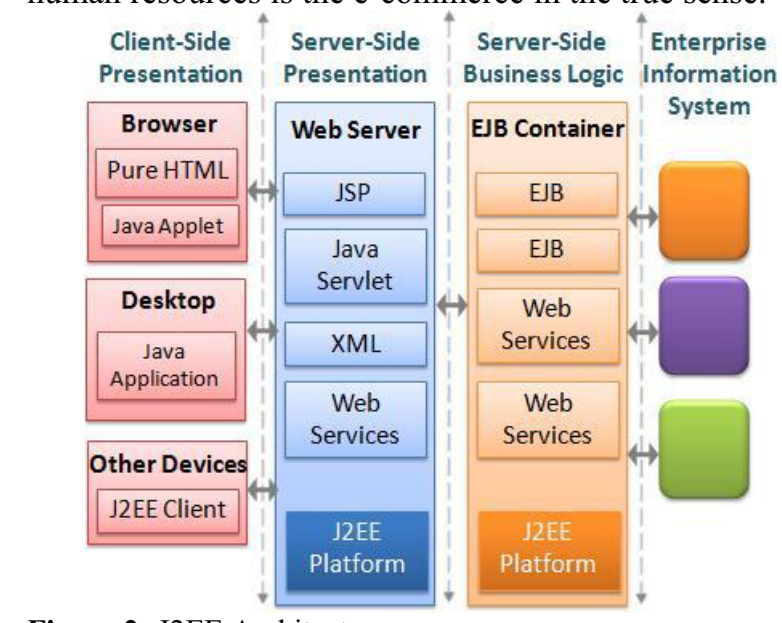

Figure 2. J2EE Architecture

\section{The financial impact of strategic decisions}

Many factors influence the formation of a strategic decision, and the impact of each factor in the decisionmaking has particularity. This makes the enterprise a lot of careful analysis of internal and external environment become a key strategic decision, "the financial impact of strategic decisions environmental factors, including the following aspects:

(1) Social, political, regulatory and public interest "Broadly speaking, the strategy must first meet the requirements of relevant laws and administrative regulations, is community-wide acceptance and is recognized by the public.

(2) Industry attractiveness and competitive conditions, "industry attractiveness is a key factor in strategic decision-making" business valuation industry and the competitive environment will directly determine its position in the industry and the basic means of competition taken.

(3)External opportunities and threats, enterprises must fully consider and seize good opportunities when they face strategic decisions, especially those that can improve the opportunities for its long-term competitive position and profitability, at the same time, we must try to avoid those that will weaken its various external threat competitive position and future operating results.

(4) Internal strengths. Weaknesses and core competitiveness, the company's strengths can attract more opportunities, weaknesses and current competitive position in the market can make some risky strategy does not even set up a decisive factor in the formation of a strategic decision is whether a company has or is likely to create a key factor in strategic decision-making as a distinctive characteristic competitiveness of enterprises to take advantage of its unique ability to seize a special opportunity, and have a competitive advantage in the marketplace.

(5)Personal ambitions of senior system, business philosophy and moral beliefs "strategic decisions are rarely made entirely through objective analysis by managers, managers of personal ambition, values, Philosophy, Attitudes to risk and so on strategic decisions has a significant impact.

E-commerce refers to the enterprise corporate financial strategy in order to seek long-term development strategy based on the overall movement of capital requirements and business trends in the analysis of internal and external environmental factors and the basis of the impact on the financial activities of the business done by global capital flows long-term, systematic and decisive plan.

Financial strategy focus of e-commerce business is the development direction of the company's future financial activities. Goals and objectives of the basic approaches and strategies of course, but also consider some of the new features is different from traditional e-commerce business. Overall e-business strategy, corporate finance goal is reasonable to mobilize, allocation and utilization of resources, to seek a balanced enterprise funds, effective flow, build their core competitiveness, and ultimately maximize enterprise value. several aspects of this goal is interrelated, "in the long run it performance of enterprise financial resources for sustainable growth and the ability to achieve capital appreciation and corporate enterprise financial ability sustained, rapid and healthy growth and development of enterprises to maintain a competitive advantage. 
Specific objectives of e-commerce enterprise financial strategy is to achieve the overall goal of corporate financial strategy developed, which provides the direction of business operations and financial strategy to achieve the goal of basic approaches and strategies, e-commerce businesses funding strategic goal is to make companies funds can be provided to meet the needs of investment, and the lowest cost of capital; investment strategy objective is to pursue a satisfactory return on investment and cash flow, market share and so satisfying enterprise financial system by the overall objective of the strategic objectives and sub-objectives. Financial strategy the overall objective is to dominate the strategic objectives in the financial system, play a leading role in the goal, because the enterprise value maximization is the ultimate expression of enterprises of all economic, strategic financial theory therefore be established as the overall objective of the financial strategy. Sub-goal is to serve the overall goal, guidance to the financial activities of a particular area of the locality of goals, including the financing of strategic goals, investment strategy and asset system objectives strategic objectives. Specific target layer is about one aspect of specific goals, such as the most appropriate scale of investment, optimal capital structure, and lowest overall cost of capital, most reasonable profit distribution rate, and so on.

According to the views of modern finance, e-commerce should also exist optimal financing structure "and traditional business, as well financing structure depends on the cost of long-term funding needs of the enterprise." We know that when the cost of debt capital is less than the cost of capital when sovereignty, debt system can obtain the appropriate financial leverage, thereby increasing the sovereign capital gains enterprise; but when leverage reaches a certain limit, continue to increase debt funding could have the opposite effect, because people will realize that bonds continue to invest risks increase, a change in the solvency of the enterprise, which requires compensation expense to take this extra risk should be obtained, therefore, will increase the cost of debt capital and financial leverage may cause the loss of "optimal capital structure should be a company's stock price can reach the largest proportion of long-term funds, and meet the conditions of this ratio is: weighted average cost of capital to a minimum.

The beginning of e-commerce development, access to finance is important, but considering the cost of financing. Attention is also critical financing structure. Debt should be generally appropriate choice, after all, in the case of a moderate increase in risk for shareholders or increased benefits. Moreover, as e-commerce and gradually into the normal track profit, tax effect is more prominent bond financing, then further reduce the risk of J2EE industries, and appropriately increase the proportion of debt financing to bring positive effects will exceed the negative effects.

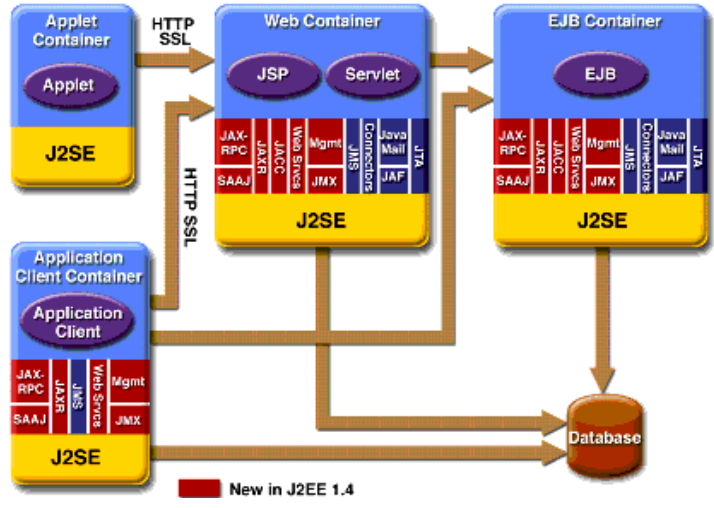

Figure 3. j2ee platform and the j2se enterprise apis

\section{The financial system is the core}

The main function of the J2EE of financial system is:

(1) to achieve the integration of supply and marketing business and financial system, "the implementation of procurement operations, automatically generates the corresponding single storage, inventory system, warehousing and other processing modules while automatic inventory costing, and transferred to the general ledger accounting vouchers modules based on the integration of the new moon brings source tracking function, can realize from the general ledger to ledger voucher to the original documents to the penetration of the query, and fully synchronized financial processing and business processes.

(2) The effective control of costs. Online financial software data imputation in terms of cost, design comprehensive data source automatically "cost system module from the inventory accounting, payroll, fixed asset system and general ledger automatically extract cost data. Each cost data will be synchronized automatically generated during" in terms of cost planning, you can prepare a comprehensive cost plan, after the end of the cost accounting and cost variance analysis results for this program automatically generate "cost forecasting and analysis, can be made to predict the cost and product cost sector forecast.

(3) Effective control of financial operations risk. Online financial software by implementing financial business integration, making the occurrence of any business will be immediately reflected in the financial account, which truly reflects the number of changes in inventory and inventory costs, and a true reflection of scattered information on the distribution channel inventory and sales information to more effectively control operational risks.

(4) Provides enterprise-level analysis of decision-making information. Online financial software is a cross-sectored, cross-regional application software system, systems store a large number of financial and business information, users can meet fully understand the business situation, the need to develop prospects and business risks, and provide predictive analysis for managers and scientific decision 
Analysis. The beginning of e-commerce development, access to finance is important, but considering the cost of financing. Attention is also critical financing structure. Debt should be generally appropriate choice, after all, in the case of a moderate increase in risk for shareholders or increased benefits. Moreover, as e-commerce and gradually into the normal track profit, tax effect is more prominent bond financing, then further reduce the risk of J2EE industries, and appropriately increase the proportion of debt financing to bring positive effects will exceed the negative effects.

This site provides ASP services can be divided into free browsing, paid downloads, and the general Internet, as the Internet of the costs and expenses the same. As for entering the site-specific information services and downloaded the software being selected, according to their complexity. Workload service pays the prescribed fee. Such costs will create complex than corporate accounting information systems. Purchased or developed accounting software to be much smaller. As a registered membership of the way, also known as club membership, that is to give full play to the advantages of a good J2EE of financial various ways, member companies can get the site fixed various information services, to build their own pages on the site; released they think need to publish information they need to download any software provided by the site; You can also use its website has commissioned software companies need to complete an accounting and financial system tasks: the website each Member companies kinds of information exchange and access to counselling and training and other educational services website.

\section{Conclusions}

The rise of e-commerce has brought to the development of new business opportunities, financial services will no longer be confined to one country or one region, but will toward internationalization, precise, computerized, J2EEoriented development "in the new environment, the study of financial system will be more valued and developed, so e-commerce based financial system research has particular practical significance.

At present, domestic and foreign research focuses on the financial system of e-commerce on the J2EE financially J2EE technology introduction to the original financial system, mainly the need for use of the J2EE in order to solve the financial problems have been studied from a J2EE application functions of financial systems (especially J2EE of financial applications) to study such consolidated statements, analysis of financial condition, remote data processing, functional analysis data storage, J2EE security solutions, etc. "in fact, the J2EE of financial electronic commerce just under a financial system mode, the current study did not conduct systematic financial system theory analysis of the new era, nor build the Financial System.

\section{References}

1. Ding Yuan Bamboo volunteerism function in building a socialist core value system. Beijing: Peking University Press, 67(2008)

2. Yan Lv. On the impact of e-commerce and innovation of financial system. Chengdu Westernization University, 46(2004)

3. Yang Fuqiang. Enterprise financial system of ecommerce era. Ningbo Vocational and Technical College, 33(2004)

4. HU Guo Liu. Corporate Financial Strategy and Financial Control. Tsinghua University Press, 195(2002)

5. Wong Jing. After the 2004 Chinese e-commerce into the financing of the times. Computer Knowledge and Technology, 979(2004)

6. Hao Liren. Practical statistical analysis. China Water Power Press, 356(2009)

7. Yang Xiaoming. SPSS Statistics in Education. Higher Education Press, 97(2004)

8. Chang Dayong, Zhang Lili. Economic System Fuzzy Mathematics. Beijing Economic Publishing House, 78(2005)

9. Zhang Wei. AHP and fuzzy theory in research evaluation. Ningxia University, 230(2002)

10. Comprehensive evaluation method HUANG Ti-yun multi-factor Fuzzy economic growth in e-commerce applications. Quantitative and Technical Economics Research, (495)2008 